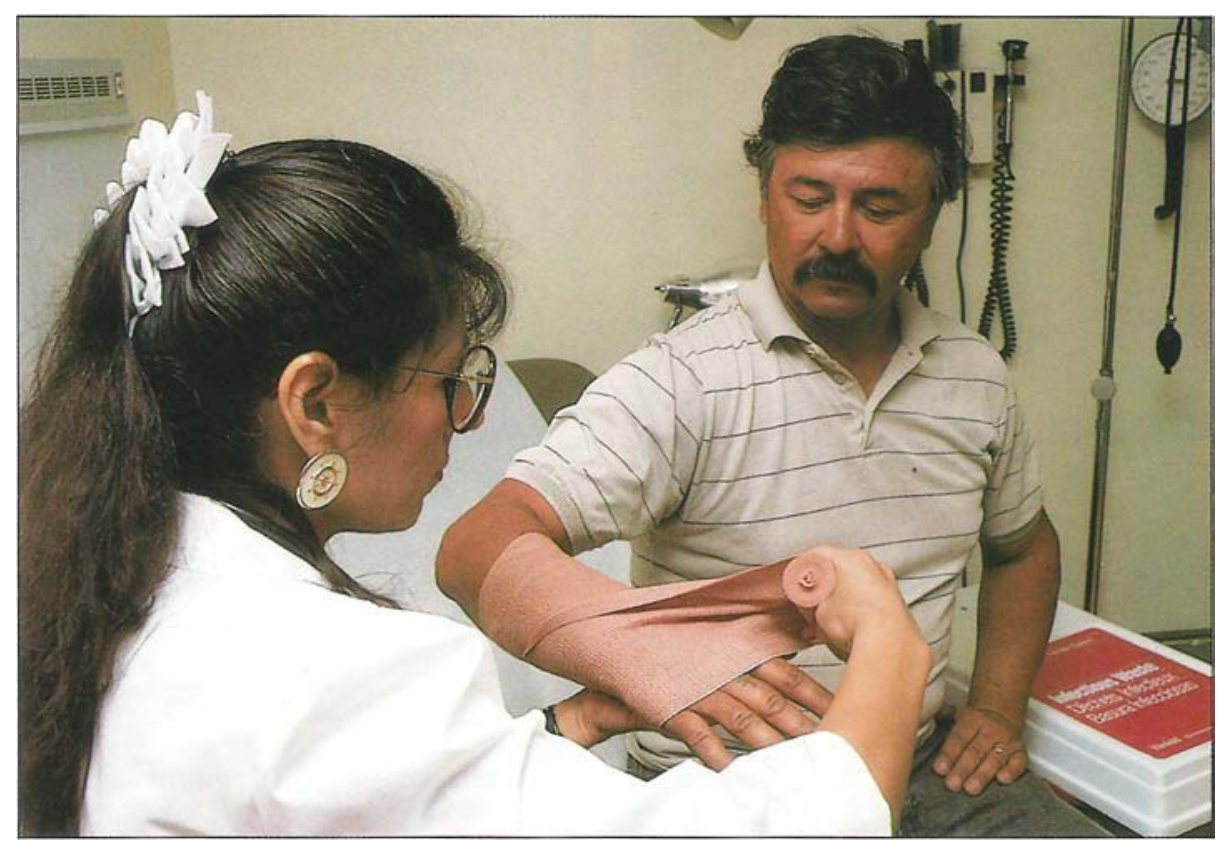

Health professional wraps chemical burn at the United Health Centers of the San Joaquin Valley.

\title{
Farmworker injury and illness: statistical guides to prevention
}

\author{
Stephen R. Sutter
}

\section{Requirements mandated by the historic statute Senate BiIl 198 in- clude identifying occupational safety and health hazards and training current supervisory and other employees in coping with general agricultural hazards. This review of accident and illness sta- tistics for agriculture may be useful in developing a written Injury and IIIness Prevention Program.}

Every California employer, including farm labor contractors (FLC's), is now required to "establish, implement, and maintain" an effective written injury and illness prevention program under the California Occupational Safety and Health Administration (Cal/OSHA) General Industry Safety Order 3203 (Senate Bill 198 of 1989).

Senate Bill 198 also directed the Department of Industrial Relations to establish a list of the 100 highest hazard industries in California. Two of the industry classifications on the high hazard list are crop production and livestock production. The list does not contain the farm labor and management services industry, which includes FLCs.
$\mathrm{Cal} / \mathrm{OSHA}$ enforcement work is being "reprioritized" to focus on industries selected from the high-hazard list. An evaluation of the Injury and Ilness Prevention Program, including interviews with a sample of employees, will be included in every Cal/OSHA inspection. Only employers with an operational program can receive penalty discounts for good faith efforts to abate or eliminate an alleged violation, or be eligible for other considerations.

Safety Order 3203 specifies that the written program include six principal elements:

-Naming of responsible individual(s);

-Identification of workplace hazards linked with the jobs and responsibilities of employees, and investigation of injuries and illnesses;

- Periodic inspections;

- Corrections of safety-related shortcomings;

-Provision of a training system for employees; and

- Establishment of a safety communication program with employees.

The element entailing hazard identification involves use of diverse information sources comprised of, but not restricted to: - Careful appraisal of worker safety complaints or suggestions. (Communica- tions with employees regarding safety must be two-way and free from any threat of retaliation.)

- Review of Cal/OSHA standards (Safety Orders) and California Department of Food and Agriculture worker safety regulations that identify hazardous work and dictate how safety is assured.

- Monitoring of work practices, work areas, and equipment, looking for potentially or plainly unsafe situations.

-Evaluation of the employer's own workers' compensation claims and the OSHA Log 200 of recordable occupational injury and illness cases.

-Investigation of injuries, illnesses, "near misses," and uncommon incidents.

- Study of accessible published statistics that show accident and illness frequencies for types of work within agriculture, and review of Material Safety Data Sheets.

\section{California farm injuries, illnesses}

Of all California farmworkers hurt on jobs in 1989, 47\% had been with their present employer for less than 1 year. Morestriking is that $17 \%$ of injuries and illnesses took place in less than 1 month of service. Similarly, $48 \%$ of reported work injury and illness cases among graders and sorters happened in the initial year of employment, $18 \%$ in less than 1 month. These data spotlight the importance of safety training for employees, particularly new hires.

Agriculture ranked third among major California industries in terms of reported nonfatal injury and illness cases per 100 workers covered by workers' compensation in 1989, according to annual data published by the Division of Labor Statistics and Research, California Department of Industrial Relations.

With 4.81 cases per 100 covered workers, agriculture was positioned behind construction (8.33) and transportation and public utilities (4.94), but ahead of state and local government (4.02), mining (3.48), manufacturing (3.46), retail trade (3.34), wholesale trade (3.33), services (2.29) and finance, insurance and real estate (1.22). In 1988, agriculture also ranked third among these 10 industry groups, with 5.08 disabling work injuries and illnesses per 100 workers covered by workers' compensation.

Nine of the 229 work-related deaths in California were in farming and related agricultural occupations. In 1988, 10 of 218 work-related deaths occurred in farming and related agricultural occupations.

Of the entire state's work-related deaths in 1989, 118 were "standards-related". These cases are presumed to be associated with California Safety Order violations. In 1988, 80 deaths were linked to OSHA violations. 


\begin{tabular}{|c|c|c|c|c|c|c|}
\hline \multirow[t]{2}{*}{ Nature of accident } & \multicolumn{2}{|c|}{ Crops } & \multicolumn{2}{|c|}{ Livestock } & \multicolumn{2}{|c|}{$\begin{array}{c}\text { Farm labor and } \\
\text { management } \\
\text { services }\end{array}$} \\
\hline & 1988 & 1989 & 1988 & 1989 & 1988 & 1989 \\
\hline $\begin{array}{l}\text { Burns and scalds } \\
\text { Contusions, crushing }\end{array}$ & 1 & 1 & 2 & 2 & - & 1 \\
\hline injuries & 8 & 9 & 11 & 12 & 7 & 6 \\
\hline Cuts, punctures & 16 & 16 & 13 & 15 & 17 & 19 \\
\hline Abrasions, scratches & 7 & 7 & 3 & 3 & 8 & 9 \\
\hline Fractures & 9 & 6 & 17 & 13 & 9 & 5 \\
\hline Strains, sprains & 43 & 46 & 36 & 39 & 35 & 40 \\
\hline Dccupational illness & 7 & 6 & 4 & 3 & 10 & 5 \\
\hline Dther or not stated & 9 & 9 & 14 & 13 & 14 & 15 \\
\hline
\end{tabular}

TABLE 4. Occupational injury incidence rates per 100 full-time workers, for U.S. agricultural production and services, 1988 and 1989, Bureau of Labor Statistics (BLS) survey*

\begin{tabular}{lcccc}
\hline \hline & \multicolumn{2}{c}{ Production } & \multicolumn{2}{c}{ Services } \\
\cline { 2 - 5 } & 1988 & 1989 & 1988 & 1989 \\
\hline Total cases & 11.7 & 11.7 & 9.2 & 9.4 \\
Lost workday cases & 6.1 & 6.0 & 5.0 & 5.2 \\
Nonfatal cases & 5.6 & 5.7 & 4.2 & 4.2 \\
Without lost workdays & 107.8 & 99.8 & 90.6 & 98.9 \\
Lost workdays & & & \\
\hline *The incidence rates representing the number of injuries and illnesses or lost workdays per 100 full-time work- \\
ers were calculated as: (N/EH)
\end{tabular}

Of the 1989 reported injuries and illnesses, 9,614 happened on crop farms. Farms and ranches producing fruits and tree nuts recorded 3,562 cases, or $37 \%$ of the crop farm total. Businesses primarily producing livestock and livestock products reported 1,796 disabling work injuries in 1989; dairy farms accounted for 864 , or $48 \%$ of the total for livestock operations.

Farm labor and management services, including farm labor contractors (FLCs), reported 3,086 disabling work injury and illness cases under workers' compensation in 1989. Other agricultural service firms, and forestry and fishing businesses reported 6,540 cases in 1989.

Strains, sprains, dislocations and hernias accounted for $43 \%$ of all work-related injuries and illnesses in California agriculture in 1989. The kind of agricultural injuries and illnesses associated with certain broad types of agricultural employers for 1988 and 1989 is shown in table 3.

\section{U.S. farm injuries and illnesses}

Safety management information can also be gathered from annual occupational injuries and illnesses surveys conducted by the U.S. Department of Labor, Bureau of Labor Statistics (BLS). The agriculture industry division in this survey, though, excludes U.S. farms with fewer than 11 employees. Injuries from job-related accidents for BLS purposes are "reportable" if they result in death, loss of consciousness, restricted work activity, transfer to another job, or medical treatment beyond first aid.

The BLS survey ranked "agriculture, forestry, and fishing" third among nine private industry sectors in 1988 and 1989 with 10.9 total cases (including fatalities) per 100 full-time workers in both years. Self-employed owner-operators are excluded from the illness and injury counts.

Occupational injury incidence rates per 100 full-time workers for agricultural production and agricultural service industries are shown in table 4. Agricultural service industries include farm labor contractors, farm management services, crop services, and landscape and horticultural services. As a whole, agricultural service industries showed lower incidence and lost workday rates than production firms.

TABLE 5. Occupational injury incidence rates per 100 full-time workers in agriculture, forestry and fishing, 1989*

\begin{tabular}{cc}
\hline \hline $\begin{array}{c}\text { Establishment size } \\
\text { (workers) }\end{array}$ & Rate \\
\hline $11-19$ & 6.4 \\
$20-49$ & 10.0 \\
$50-99$ & 12.0 \\
$100-249$ & 13.5 \\
$250-499$ & 13.5 \\
$500-999$ & 12.6 \\
\hline
\end{tabular}

"Source: BLS News Release USDL 90-582, Nov. 14, 1990.
The incidence rates representing the number of injuries and illnesses or lost workdays per 100 full-time workers were calculated as: $(\mathrm{N} / \mathrm{EH}) \times 200,000$, where $\mathrm{N}$ $=$ number of injuries and illnesses or lost workdays, $\mathrm{EH}=$ total hours worked by all employees during calendar year (not including vacations, holidays and leaves), and $200,000=$ base for 100 full-time workers (working 40 hours/week, 50 weeks per year).

\section{Discussion}

This review of selected published statistics from government agencies provides agricultural managers and supervisors with one information source to use in a system for identifying occupational hazards - the most technically challenging requisite of the standard for small to midsized agricultural employers that do not have safety professionals on their staff. With a background of information on haz ard identification the process of formally identifying workplace hazards and devising safety measures and training programs can proceed and be documented. These data also provide some rough standards for evaluating the current and future safety performance of the operation.

No single data base is sufficient to provide a complete picture of the injury and illness status of agricultural workers. Data from workers' compensation authorities may underestimate the magnitude of the problem because of underreporting. Only by pooling many different data files can a valid composite representation be gained.

Injury and illness data portray what happened, but not why injuries take place. These data do not address the areas of safety engineering, work organization, supervision, education, medical care access, first aid and emergency medical response. Why injuries occur is a detailed question of interest to employers. Research that investigates these greater questions is needed.

A two-page written (English/Spanish) model safety program, additional forms for documentation (including accident investigation), required $\mathrm{Cal} / \mathrm{OSHA}$ posters, inventory of training resources and copies of selected Cal/OSHA safety orders affecting agricultural employers are available from the author (1720 S. Maple Avenue, Fresno, CA 93702, (209) 488-3285). The Cal/OSHA Consultation Service also offers free assistance in developing safety programs. Your workers' compensation carrier and farm organizations can also assist you in safety management.

S. R. Sutter is Area Farm Advisor, Personnel Management, Fresno, Kings, Madera \& Tulare counties 